\title{
Relationship of Neurovascular Elements to Neuron Injury during Ischemia
}

\author{
Gregory J. del Zoppo \\ Departments of Medicine and Neurology, University of Washington, Seattle, Wash., USA
}

\section{Key Words}

Ischemic stroke $\cdot$ Neurons $\cdot$ Neurovascular unit Proteases • Hemorrhagic transformation

\begin{abstract}
Occlusion of flow to the brain regions identifies regions of vulnerability within the vascular territory at risk, which coalesce to become the mature ischemic lesion. A large number of unsuccessful clinical trials have focused on neuron and extravascular targets in humans that have shown apparent salvage in preclinical models. However, the observation that microvessel and neuron responses to ischemia occur simultaneously in these regions suggest that the responses could be coordinated. This presentation examines evidence in support of the conceptual 'neurovascular unit' and its application to the setting of acute intervention trials in ischemic stroke. There are no uniform reasons for which nonvascular interventions, as a class, have not been successful in clinical trials, but both the clinical observations and the hypothesis imply the need to understand interactions with the neurovascular unit as a prelude to further neuron protectant trials.

Copyright $\odot 2009$ S. Karger AG, Basel
\end{abstract}

\section{Introduction}

Focal ischemia in the brain results from occlusion of brain-supplying arteries and the abrupt reduction in $\mathrm{O}_{2}$ and nutrient supply to the neuron and the glial compart-

\section{KARGER}

Fax +4161306 1234

E-Mail karger@karger.ch

www.karger.com (c) 2009 S. Karger AG, Basel

Accessible online at: www.karger.com/ced ments. Within the territory at risk, maturation of the ischemic lesion by $24 \mathrm{~h}$ after arterial occlusion passes through the stages of tissue infarction, involving leukocyte infiltration, and tissue 'rarefaction', and ending in gliosis and tissue cavitation. The molecular processes underlying cell damage and repair and the mechanisms involved in the maturation of the lesion leading to brain infarction are complex and not yet completely worked out. Some of these processes are summarized in table 1 . Of increasing interest are the alterations in the intimate relationships between neurons and their microvascular supply initiated by focal ischemia. Viewing the multifaceted molecular mechanisms of injury maturation from the perspective of the neuron-vascular interactions provides a framework with which to evaluate proposed cell damage and repair processes, their clinical implications, and potential interventions. This presentation addresses the basis for and implications of this conceptual framework.

\section{The Neurovascular Unit}

The control and modulation of regional and local flow in the absence of ischemic injury is dependent upon neurovascular coupling [1-3]. To some degree, neurovascular coupling reflects the presence and form of neuronal activation, and the functional efforts of intact neurons. The proximity of microvascular endothelial cells to the circumferential astrocyte end-feet, and the support of astrocytes for neurons suggest that communication could 
Table 1. Processes involved in ischemic injury of the CNS

Metabolic events

Generation of free radicals NO generation

Protein oxidation

Lipid peroxidation

Depolarization by neurons in evolving infarction and peri-infarct area

Acidosis (lactic acidosis)

$\mathrm{Ca}^{2+}$-mediated cell demise

Failure of $\mathrm{Ca}^{2+}$ exclusion mechanisms

Increase in cytosolic $\mathrm{Ca}^{2+}$

Activation of lipolytic pathways

Alterations in protein phosphorylation

Depletion of ATP stores with depression of glucose metabolism

Impaired mitochondrial function

Proteolysis

Protein synthesis

Cellular events (acute)

Activation of cell signaling pathways

Decreased endothelial cell matrix-adhesion receptor expression

Decreased astrocyte matrix-adhesion receptor expression

Detachment of astrocyte end-feet from vascular basal lamina matrix

Degradation of vascular basal lamina matrix components

Expression of matrix proteases

Matrix metalloproteinases

Cathepsins

Heparanase

Serine proteases (e.g. urokinase)

Increased microvascular permeability

Astrocyte swelling

Neuron swelling

Release of glutamate from neurons

Depolarization by neurons in evolving infarction and peri-infarct area

Expression of cytokines

Generation of platelet activating factor

Activation and appearance of inflammation

Activation of endothelial cell leukocyte adhesion receptors

Activation of PMN leukocytes and monocytes

Adhesion and transmigration of PMN leukocytes

Platelet activation

Microglial cell activation, shape alterations, and migration

\section{Tissue injury}

Edema formation

Cellular swelling

Focal 'no-reflow' within ischemic regions

Increased microvascular permeability with leakage

Angiogenesis with capillary bud formation

Cell demise

Hemorrhagic transformation

Liquefaction and cavitation also be directed from microvessels to the neurons they supply $[4,5]$. This surmise suggests the hypothesis that neuron-microvascular interactions can be described by a 'neurovascular unit' which consists of microvessels (endothelial cells, basal lamina matrix, astrocyte end-feet and pericytes), astrocytes, neurons, and their axons, in addition to other supporting cells (e.g. microglia and oligodendroglia). This provides a framework for considering bidirectional intercommunication between neurons and their neighboring supply microvessels via the intervening astrocytes. The resilience of the 'unit' to reduction in flow or to flow cessation is unclear, but the processes are likely to be complex as adjacent units would be connected through their common microvessels and through dendritic connections. This affords intercommunication and protected perfusion at the same time. Alterations in microvessel integrity could have follow-on effects within the neurovascular unit, also affecting neuronal function [5].

\section{Microvessel-Neuron Relationships}

Overall, the cerebral vascular circuit and the microvasculature contribute to a low-pressure high-flow system. The arrangement or architecture of the microvasculature within the anterior cerebral circulation accommodates dynamic changes in flow and is determined by the organ development and by the regional location. During development, the relative positions of microvessels and neurons to one another involve microvascular growth along matrix paths [6-10]. Capillaries, astrocytes and endothelial cells interact to form the intervening basal lamina barrier and the interendothelial tight junctions as part of the permeability barrier [11-17]. Elegant xenograft experiments have demonstrated that the close apposition of endothelial cells and astrocyte end-feet are required for the appearance of the permeability barrier phenotype [18]. In general, capillaries are located within a mean of $30 \mu \mathrm{m}$ of the nearest neighboring neuron [19]. Within the corpus striatum, the distribution of distances between neurons and their nearest microvessels is rightskewed, but highly ordered and predictable [19]. The capillary arrangement has branch points at approximately $30-\mu \mathrm{m}$ intervals [19]. The branching of the capillaries allows diversion of flow to patent capillaries/microvessels to circumvent occluded vessels. In the cerebral gray matter, there is a hierarchical organization of the arterial supply, as stacked hexagonal arrays descending from the pial supply to the white matter border [20-22]. The branching 
Table 2. Matrix adhesion receptors of the microvasculature

\begin{tabular}{|c|c|c|}
\hline Adhesion receptors & Cell source & $\begin{array}{l}\text { Response to } \\
\text { ischemia }\end{array}$ \\
\hline $\begin{array}{l}\text { Integrin subunit } \alpha_{1} \\
\text { Integrin subunit } \alpha_{3} \\
\text { Integrin subunit } \alpha_{6} \\
\text { Integrin subunit } \alpha_{v} \\
\text { Integrin subunit } \beta_{1}\end{array}$ & $\begin{array}{l}\text { endothelial cells } \\
\text { endothelial cells } \\
\text { endothelial cells } \\
\text { endothelial cells } \\
\text { endothelial cells }\end{array}$ & $\begin{array}{l}\text { decrease } \\
\text { decrease } \\
\text { decrease } \\
\text { increase } \\
\text { decrease }\end{array}$ \\
\hline $\begin{array}{l}\text { Integrin subunit } \alpha_{1} \\
\text { Integrin subunit } \beta_{1} \\
\alpha \beta \text {-Dystroglycan }\end{array}$ & $\begin{array}{l}\text { astrocyte end-feet } \\
\text { astrocyte end-feet } \\
\text { astrocyte end-feet }\end{array}$ & $\begin{array}{l}\text { decrease } \\
\text { decrease } \\
\text { decrease }\end{array}$ \\
\hline
\end{tabular}

within these microvessel arrays also allows diversion of flow around impediments or occlusions within one or more capillary branches. Within the white matter, capillaries are arranged in line with axons and comprise $\sim 10 \%$ of the density of capillaries found within the gray matter [23]. The branching pattern within the white matter is not so clearly described. These considerations indicate that there are region-specific arrangements of the microvasculature. These accord with differences in regional cerebral blood flow in which flow is lowest in the striatum and highest in the cortical gray matter.

\section{Vascular Matrix Scaffold and Matrix Adhesion Receptors}

The basal lamina of cerebral microvessels provides a scaffold on which the endothelium and the glial compartments interact. The principal components of the basal lamina consist of the extracellular matrix (ECM) proteins laminin 1 (and laminin 5), collagen type IV, and fibronectin of cellular origin [24]. Minor components consist of perlecan, nidogen, and other proteoglycans [25]. In general, the ECM composition of the basal lamina is distinct from that separating cells in the neuropil.

The integrity of the microvasculature depends upon the proximity of astrocyte end-feet to the endothelium: both are required for the formation of the basal lamina matrix and for the formation of the permeability barrier $[11,18,26]$. The permeability barrier was originally attributed to interendothelial cohesion by the tight junction proteins ZO-1, occludin, and claudin-5 [14-17]. Disruption of the permeability barrier has been associated with changes in tight junction protein expression, although those changes are not rapid. Increased perme- ability of the microvasculature to small molecules (e.g. albumin) can occur as early as $2-3 \mathrm{~h}$ following middle cerebral artery occlusion (MCA:O) in relevant cerebral ischemia models [27]. More recently, it has been proposed that adhesion of both cell components to the intervening matrix via integrin receptors and dystroglycan may play a role in preserving this barrier (see below).

The matrix provides the second barrier, which limits the transmigration or leakage of blood cells: erythrocytes during hemorrhage and leukocytes in response to inflammatory stimuli (e.g. the inflammatory phase of ischemia). The integrity of the microvasculature is also affected by the presence of pericytes located within the matrix or vessel wall histiocytes within larger vessels [28].

The ultrastructure and integrity of cerebral capillaries depends upon their location and regional tissue composition. Integrin and dystroglycan receptors appear to bind endothelial cells and astrocyte end-feet to the individual intervening matrix components (table 2). Specifically, $\alpha \beta$-dystroglycan is expressed by astrocyte end-feet on all cerebral vessels, while integrin $\alpha_{6} \beta_{4}$ is expressed on large penetrating vessels of the gray matter and all microvessels in the white matter $[23,29]$. $\beta_{1}$-integrins are expressed by the endothelium of all cerebral microvessels also within both the gray and the white matter [23, 30, 31].

Focal ischemia initiates rapid loss of (a) integrity of the ECM within the microvasculature, and (b) matrix adhesion receptors (or their conformation). Loss of the ECM corresponds to the appearance of hemorrhagic transformation within the ischemic territory [32]. A significant rapid loss of the $\beta_{1}$-integrin subunits $\alpha_{1}, \alpha_{3}$, and $\alpha_{6}$, the astrocyte integrin $\alpha_{6} \beta_{4}$, and dystroglycan occurs following MCA:O within the ischemic core $[29,30,33]$. Interestingly, transcription of $\beta_{1}$-integrin increases on microvessels within multiple adjacent cores, suggesting that the microvascular endothelium actively attempts to generate more $\beta_{1}$-subunits $[34,35]$. This coincides with the upregulation of integrin $\alpha_{v} \beta_{3}$ on the microvasculature in the same regions [36].

Loss of the matrix proteins has been attributed to the rapid generation of members of several protease families. Heo et al. [37] have demonstrated the rapid appearance of the latent matrix metalloproteinases (pro-MMP)-2 and -9 in the ischemic territory following MCA:O (nonhuman primate) $[37,38]$. pro-MMP-9 is associated with the appearance of hemorrhagic transformation [37]. pro-MMP2 generation is directly related to the appearance of neuron injury within the ischemic core regions [37]. Proteases associated with the activation of pro-MMP-2 also appear within this territory in temporal context [38]. Ca- 
thepsin L, a member of the cysteine protease family, is generated rapidly in excess in the ischemic regions following MCA:O and accompanies degradation of perlecan and laminin within the microvasculature [39]. Heparanase is also generated in temporal and topographic context [39]. Among serine proteases that appear following $\mathrm{MCA}: \mathrm{O}$, plasmin is likely generated by the appearance of urokinase (u-PA) in association with its receptor u-PAR on microvessels and nearby neurons [38]. While these proteases appear within the ischemic core(s) and the ECM of the microvasculature is disrupted within this territory, there is still little direct proof that this is due to the proteases so far identified in their active form. Nonetheless, it is likely that these ECM-degrading proteases do participate in changes within the microvasculature. As one recent example, blockade of MMP-like activity by the general inhibitors GM6001 and 1,10-phenanthroline prevents degradation of $\beta$-dystroglycan from murine primary cerebral astrocytes subject to experimental ischemia [23].

Another important feature of the ultrastructural changes in the microvasculature is the observation that proteases that degrade certain ECM components appear simultaneously on the microvessels and neurons in close proximity. These include u-PA, cathepsin L, heparanase, and pro-MMP-2 [37-39]. The mechanisms causing the coincident appearance of these proteases on several elements within the microvascular unit are not known, but they do reinforce the impression that events within different elements of microvascular units within the target territory can be coordinated during focal ischemia.

In summary, (a) microvessel responses and neuron injury occur in the same time frame and the same subregions of ischemic injury; (b) an ordered relationship exists between microvessels and neighboring neurons within the susceptible territory; (c) rapid significant alterations in the matrix of the vascular compartment and in the nonvascular compartment of the ischemic territory occur, and (d) the loss of matrix adhesion receptors that accompanies ECM degradation can be prevented, in part, by inhibition of MMP-like proteases.

These observations suggest a hypothesis that links both neuron and microvascular functions and their responses.

\section{A Hypothesis}

The rapid, simultaneous and coincident appearance of matrix proteases by microvessels and their adjacent neurons implies coordinate responses of these elements of the neurovascular unit to focal ischemia [40]. While it is apparent that cytokine and chemokine generation occurs within the region of the evolving ischemic lesion, the coincident neuron-microvascular events are heterogeneously scattered within the region among uninjured microvessel-neuron pairs early following MCA occlusion [19]. The upregulation of $\beta_{1}$-integrin transcripts within microvessels in the boundaries of adjacent subregions of injury lends further support to a microvascular component of the evolving ischemic lesion, in which neurons are irreversibly injured [35]. These and related observations provide a basis for a hypothesis that states that focal ischemia can initiate coordinated events within the microvasculature and nearby neurons in which both elements behave as a unit. These are typified by alterations in both microvascular and extravascular ECM, and the rapid coordinate appearance of members of four families of proteases by adjacent microvessels and neurons in the evolving ischemic core.

One of the implications of this hypothesis is that neurons and the microvascular endothelium can communicate in both directions. Rather than a unidirectional dependence of regional microvascular flow and dynamics upon neuron signaling, the proximity of the endothelium to astrocyte end-feet and the bifunctional nature of their matrix adhesion receptors imply that communication is possible across the matrix. Both integrin and dystroglycan receptors can indicate to the cell the nature of its environment, and can also participate in events that involve cell activation. Efforts are underway to understand if this is possible in the cerebral microvasculature.

Focal ischemia in experimental systems alters endothelial cell-astrocyte relationships via its matrix receptors $[23,29,30,35]$. The implications for ischemic stroke are that (a) efforts to preserve or rapidly re-establish flow through the threatened microvascular bed are likely to reduce neuron injury within a regional network; (b) 'neuron protection' per se may not be sufficient if the astrocyte-endothelial cell relationships are disrupted by ischemia; (c) preservation of the matrix-matrix receptor interactions could contribute to preservation of neuron/ neurovascular function, and (d) preservation of astrocyte function would seem essential for maintaining the normal function of the neurovascular unit. Given our natural limitations in detecting small improvements in function clinically, efforts that successfully maintain neurovascular function in the face of focal ischemia may not be detectable in this setting. However, experience with acute interventions so far should give us a view of whether this direction of enquiry has merit.
68

Cerebrovasc Dis 2009;27(suppl 1):65-76 del Zoppo 
Another implication of this hypothesis is that events occurring during focal ischemia within cerebral microvessels are linked to the actions of neurons supplied by those microvessels, via the syncytium of astrocytes, and that strategies designed to protect neurons should also protect function within the entire neurovascular unit.

\section{Acute Interventions in Ischemic Stroke and the Neurovascular Unit}

In the last two decades, considerable effort has been expended to treat patients acutely after the onset of ischemic stroke when it was shown that neurological benefit could be gained with arterial recanalization procedures. Prospective controlled randomized trials have examined two classes of treatments: (a) 'neuroprotectant' agents, and (b) antithrombotic agents. Together, these compounds include NMDA receptor antagonists (e.g. cerestat, citicholine), free radical scavengers (e.g. tirilazad mesylate, NXY-059), anti-inflammatory immune inhibitors (e.g. enlimomab), select antiplatelet agents (e.g. abciximab), and plasminogen activators (e.g. rt-PA, singlechain urokinase, scu-PA; fig. 1).

\section{Neuron Protectants}

Agents with demonstrated ability to decrease neuron demise in either isolated cell culture or in small animal models of focal cerebral ischemia have been termed 'neuroprotectants'. The presumed target of activity of the agents is the neuron, and a few mechanisms subjected to inhibition include $\mathrm{Ca}^{2+}$ regulation and transit, neurotransmitter release, and cell demise pathways. While fundamental studies have identified compounds with neuron salvage properties in preclinical model systems, use of these compounds in the clinical setting has, for various reasons, proved unsuccessful. The recently terminated program to develop NXY-059 for acute intervention in ischemic stroke is instructive [41-45]. The SAINT-1 trial, a prospective placebo-controlled randomized multicenter study of NXY-059 on stroke outcome, was equivocal [42], while the larger phase III prospective trial, SAINT-2, did not demonstrate a significant improvement in stroke outcome with NXY-059 [44]. Among the reasons posited, the agent known to quench free radicals did not cross the permeability barrier into the CNS, to the abluminal microvascular interface where free radical generation is known to occur [46]. Other agents have also proven to be unhelpful in the setting of focal isch-

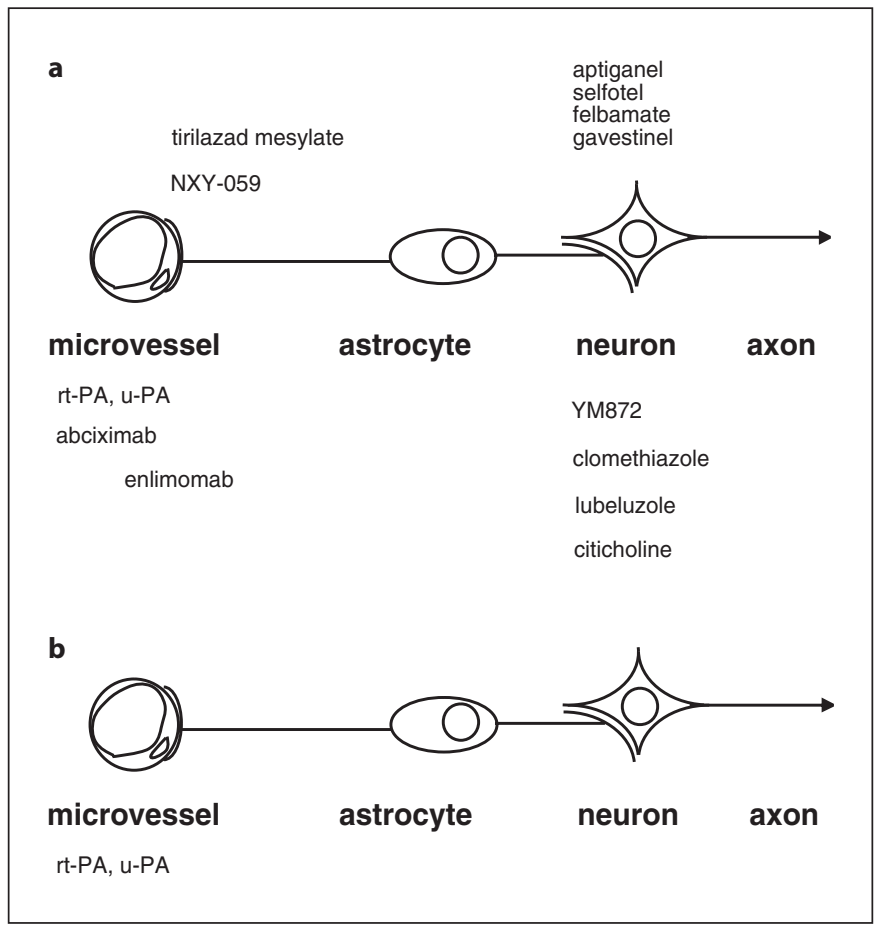

Fig. 1. Relationship of targets of acute intervention for ischemic stroke evaluated by prospective well-controlled clinical trials. a General classes of agents (and specific agents within specific classes where applicable) that have been tested with results to date. All have had activity in animal focal ischemia models. b Agents that have been shown to have efficacy, and can be applied safely when strict rules are followed. Note that all of the agents directed against neuron-associated targets (e.g. NMDA receptors, glycine antagonists) and some against the generation of reactive oxygen species (free radicals) known to appear at the microvessel-neuropil interface have not been shown to have activity in human patients. Only antithrombotic agents and, in particular, plasminogen activators have shown activity.

emia despite acute intervention. These can be mapped relative to their presumed cellular target(s) in the neurovascular unit (fig. 1). While many agents with putative neuron protectant activity have been shown to reduce neuron injury in vitro or decrease injury volume following MCA:O, their actual targets may be nonneuronal. This raises the concern that data specific for the intended target, the impact of target injury on neuron viability, and the relation of those responses to the tissue responses would be of interest for assessing the relevance of these and related compounds to the clinical setting.

For neuron protection, these considerations raise a number of questions: Why have agents shown to protect neurons in model systems been uniformly unsuccessful 
in clinical trials? Are there characteristics of human cerebral responses to ischemia that current brain injury models cannot reproduce? Can restitution of flow through an acutely thrombosed cerebral artery limit injury progression in all patients?

\section{Antithrombotic Agents}

The vascular-thrombotic nature of the majority of ischemic strokes draws attention to the potential benefit of antithrombotic agents in treatment, including antiplatelet agents, anticoagulants, and plasminogen activators. Antiplatelet interventions are employed for secondary prevention of recurrent ischemic events after a signal TIA or ischemic stroke, while anticoagulants are employed for primary prevention of thromboembolic events from nonvalvular atrial fibrillation and select prosthetic valve devices. The potential role(s) of antithrombotic agents in microvascular disease, typified by lacunar lesions or neuropsychiatric lupus, has not been defined, but consideration of their use is clinical. For ischemic strokes without clear etiology, well-controlled oral anticoagulation appears to have no advantage over aspirin [47]. Careful management of patients with acute infusion of the plasminogen activator rt-PA provides consistent improvement in their outcome [48]. To date, the prudent use of rt-PA provides the most definitive reduction in neuron injury.

Early experience in the setting of stroke employed urokinase (u-PA) or streptokinase (SK). These agents have since been superseded by the recombinant form of the endogenous tissue plasminogen activator (rt-PA), in single (alteplase) and two-chain (duteplase) forms and other derivatives of rt-PA (including r-PA; tenecteplase, TNK), and other exogenous PAs. Each of the PAs targets fibrinogen and fibrin within the thrombus lattice. t-PA is a 527amino-acid single chain, that is converted to the twochain form by plasmin cleavage of the arg275-isoleu276 linkage $[49,50]$. Both the single-chain and two-chain forms have similar catalytic efficiencies. The kinetically preferential cleavage of fibrin (in the presence of fibrinbound plasminogen) over fibrinogen underlies the impression that both forms of rt-PA are fibrin selective. The $\mathrm{t}_{1 / 2}$ of both forms of rt-PA is $\sim 3-8 \mathrm{~min}$ in humans following a single infusion, but the biologic $\mathrm{t}_{1 / 2}$ is believed to be somewhat longer, accounting for delayed hemorrhage from hemostatic thrombi $[51,52]$. The thrombus selectivity and catalytic efficiency of TNK are very similar to rtPA $[53,54]$. These characteristics allow for a single bolus injection. Additionally, no changes in fibrinogen and a modest decrease in plasminogen accompany bolus TNK.
Recombinant desmoteplase (DS-PA) is derived from the saliva of the vampire bat (Desmodus species) and has properties distinct from t-PA. The fibrin-binding of the DS-PAs depends entirely upon the presence of the finger domain; the catalytic efficiency of plasminogen activation by $\alpha_{1}$ DS-PA is $\sim 200$-fold greater than t-PA in the presence of fibrin $[55,56]$. Additional studies suggested enhanced hemorrhage from regions of vascular injury with $\alpha_{1}$ DS-PA [57]. Of these PAs, only the rt-PAs have been developed through to the demonstration of reduced injury in preclinical models, and improved neurological outcome in patients.

Recanalization of carotid artery territory occlusions by intravenous infusion techniques has been achieved in $34-59 \%$ of patients treated within $8 \mathrm{~h}$ of symptom onset [58-61]; but early studies using direct catheter-dependent SK or u-PA delivery reported recanalization of symptomatic carotid artery territory occlusions in $46-90 \%$ of patients treated within the same time frame $[62,63]$. In those studies, $18-33 \%$ of treated patients suffered hemorrhagic transformation within the ischemic territory. Clinical improvement was observed in a substantial number of those patients, although outcomes were not quantitatively assessed.

Acute recanalization of MCA division and branch occlusions occurred more frequently than ICA occlusions [58]. Mori et al. [61] first demonstrated that patients treated with duteplase had improved recanalization and a significantly better clinical improvement at 30 days than those treated with placebo. Hemorrhagic transformation occurred in $29-53 \%$ of treated patients in those studies [58-61]. Those studies demonstrated both the feasibility and safety of exposure to PAs and were the first to indicate that re-establishment of flow in the CNS could improve neurological outcome. They suggested, in more contemporary terms, that preservation of flow to/ through the microvascular components of the neurovascular unit could preserve neuron function.

The National Institute of Neurological Disorders and Stroke (NINDS)-funded two-part, four-armed, placebocontrolled outcome study of rt-PA in patients entered within $3 \mathrm{~h}$ from ischemic stroke symptom onset further supports the possibility that microvascular flow/patency could underlie preservation of neuron function [48]. rtPA recipients displayed a significant $11-13 \%$ absolute increase over placebo in the number of patients with no or minimal disability/deficit in Barthel index, modified Rankin scale (mRS) score, Glasgow outcome scale score, and NIHSS, at 3 and 12 months [48]. 
Table 3. Efficacy and hemorrhagic transformation: carotid territory ischemia, intravenous delivery

\begin{tabular}{|c|c|c|c|c|c|c|c|c|c|}
\hline Study & Agent & Patients & $\Delta(\mathrm{T}-0), \mathrm{h}$ & Outcome & $\%$ improved & \multicolumn{3}{|c|}{ Hemorrhage } & $\begin{array}{l}\text { Refer- } \\
\text { ence }\end{array}$ \\
\hline Abe & $\mathrm{C}$ & 56 & $<720$ & $\mathrm{~N}^{\mathrm{b}}$ & 47 & 0 & 0 & & {$[80,81]$} \\
\hline \multirow[t]{2}{*}{ Atarashi } & $\mathrm{u}-\mathrm{PA}$ & 191 & \multirow[t]{2}{*}{$<120$} & \multirow[t]{2}{*}{$\mathrm{N}^{\mathrm{b}}$} & 45 & 2 & 0 & 1.0 & \multirow[t]{2}{*}[82]{} \\
\hline & $\mathrm{C}$ & 194 & & & 44 & 1 & 0 & 1.1 & \\
\hline Otomo & C & 188 & $<120$ & $\mathrm{~N}^{\mathrm{b}}$ & 41 & 1 & 0 & 0.5 & {$[83]$} \\
\hline \multirow[t]{2}{*}{ Otomo } & rt-PA & 171 & \multirow[t]{2}{*}{$<120$} & \multirow[t]{2}{*}{$\mathrm{N}^{\mathrm{b}}$} & 59 & 2 & 0 & 1.1 & \multirow[t]{2}{*}[84]{} \\
\hline & $\mathrm{u}-\mathrm{PA}$ & 184 & & & 55 & 3 & 0 & 1.6 & \\
\hline \multirow[t]{2}{*}{$\overline{\text { Abe }}$} & rt-PA & 145 & \multirow[t]{2}{*}{$<72$} & \multirow[t]{2}{*}{$\mathrm{N}^{\mathrm{b}}$} & 66 & 3 & 0 & 2.0 & \multirow[t]{2}{*}[85]{} \\
\hline & $\mathrm{u}-\mathrm{PA}$ & 77 & & & 45 & 6 & 0 & 7.8 & \\
\hline Haley & rt-PA & 10 & $<1.5$ & $\mathrm{~N}^{\mathrm{c}}$ & $60^{g}$ & 0 & 0 & & {$[86]$} \\
\hline MAST-E & SK & 156 & $<6.0$ & $\mathrm{M}^{\mathrm{d}}$ & $34^{\mathrm{g}}$ & 63 & 33 & $21.0^{\mathrm{g}}$ & {$[87]$} \\
\hline & $\mathrm{C}$ & 154 & & & 18 & 57 & 4 & 3.0 & \\
\hline$\overline{\mathrm{ASK}}$ & SK & 165 & $<4.0$ & $\mathrm{M}^{\mathrm{d}}$ & $36^{\mathrm{g}}$ & 33 & 23 & $13.2^{\mathrm{g}}$ & {$[88]$} \\
\hline & $\mathrm{C}$ & 163 & & & 21 & 23 & 5 & 3.1 & \\
\hline MAST-I & SK & 313 & $<6.0$ & $\mathrm{M}^{\mathrm{d}}$ & $25^{\mathrm{g}}$ & 60 & 21 & $6.7^{\mathrm{g}}$ & [89] \\
\hline & $\mathrm{C}$ & 309 & & & 12 & 27 & 2 & 0.7 & \\
\hline ECASS & rt-PA & 313 & $<6.0$ & $\mathrm{D}^{\mathrm{f}}$ & $36^{\mathrm{g}}$ & 72 & 62 & $19.8^{\mathrm{g}}$ & {$[64]$} \\
\hline & C & 307 & & & 29 & 93 & 30 & 6.5 & \\
\hline NINDS I & rt-PA & 144 & $0-3.0$ & $\mathrm{~N}^{\mathrm{c}}$ & 47 & - & 13 & $5.6^{\mathrm{g}}$ & {$[48]$} \\
\hline & $\mathrm{C}$ & 147 & & & 39 & - & 3 & 0.0 & \\
\hline NINDS II & rt-PA & 168 & $0-3.0$ & $\mathrm{D}^{\mathrm{f}} / \mathrm{N}^{\mathrm{c}}$ & 48 & - & 21 & $7.1^{\mathrm{g}}$ & {$[48]$} \\
\hline
\end{tabular}

$\Delta(\mathrm{T}-0)=$ Interval from onset to treatment; $\mathrm{SK}=$ streptokinase; $\mathrm{u}-\mathrm{PA}=$ urokinase plasminogen activator (urokinase); $\mathrm{rt}-\mathrm{PA}=\mathrm{re}-$ combinant tissue plasminogen activator; $\mathrm{C}=$ control; $\mathrm{N}=$ neurological outcome; $\mathrm{M}=$ mortality; $\mathrm{D}=$ disability.

${ }^{a}$ Percent patients displaying parenchymal hemorrhage. ${ }^{b} \mathrm{~N}$, neurological outcome. ${ }^{\mathrm{c}} \mathrm{N}$, neurological outcome according to scoring instrument, e.g. National Institutes of Health Stroke Scales (NIHSS) score. ${ }^{\mathrm{d}} \mathrm{M}$, early mortality. ${ }^{\mathrm{e}} \mathrm{M}$, mortality at 3 or 6 months. ${ }^{\mathrm{f}} \mathrm{D}$, best disability outcome (modified Rankin Scale (mRS) score) at 3 months. ${ }^{\mathrm{g}}$ Statistically significant differences. ${ }^{\mathrm{h}}$ ECASS-II definition.

Three further phase III prospective, randomized safety and efficacy studies of intravenous rt-PA (alteplase) broadened these impressions (table 3). The European Cooperative Acute Stroke Study (ECASS) compared rtPA to placebo within $6 \mathrm{~h}$ of symptom onset; although, at 3 months, there was no significant difference between the two groups in disability outcome [64]. Discarding patients who were entered in violation of the inclusion criteria indicated an 11-12\% absolute improvement (mRS 0 or 1) in the rt-PA-treated group over the placebo group
$[64,65]$. In ECASS-II, a favorable outcome (mRS $=0$ or 1$)$ was seen in $40.3 \%$ of rt-PA patients compared to $36.6 \%$ of placebo patients [66]. Cerebral hemorrhage causing death or deterioration was significantly more frequent in the rt-PA group than the placebo group (11.7 vs. 3.1\%). Recent experience from study of patient treatment within a broader acquisition time from symptom onset has been encouraging [67, 90]. Given variations in the outcome differences, the trends (in ECASS and ECASS-II) and the benefits (in NINDS and ECASS-III) are consistent. 
These and other studies have also suggested significant contributors to the risk of hemorrhage from intravenous plasminogen activators. Contributors include excessive time from the onset of symptoms to treatment, low body mass index, diastolic hypertension, older age, and the use of rt-PA $[48,58,68-71]$. The appearance of 'early signs of ischemia' on the initial CT scan is also associated with an increased risk of hemorrhage and demise [64]. Taken together, the results of the ECASS and NINDS studies indicate the enormous importance of patient selection to reduce the hemorrhagic risk accompanying the use of plasminogen activators in acute stroke.

Evidence with TNK and rDS-PA is conflicting and incomplete. TNK has been examined in an open dose-escalation safety study of patients entered with qualifying strokes compatible with the criteria for the NINDS-sponsored rt-PA study [72]. The escalation was terminated when 2 of 13 patients suffered symptomatic intracerebral hemorrhage in the $0.5-\mathrm{mg} / \mathrm{kg}$ tier (compared to no hemorrhages in the lower doses). To date, there are no data regarding the ability of TNK at this or lower doses to achieve recanalization or preservation of neuronal function.

In contrast, the ability of rDS-PA to achieve recanalization and preservation of neuronal function was tested through phase II and phase III formats using magnetic resonance technology to define a target population. Note should be made that no dose-equivalency studies comparing $r D S-P A$ with rt-PA have been performed. The first study (DIAS) was a phase II blinded placebo dose-finding efficacy trial that initially compared fixed doses of 37.5 and $50 \mathrm{mg}(\mathrm{n}=13)$, then $25 \mathrm{mg}(\mathrm{n}=17)$ of $\mathrm{rDS}$-PA with placebo $(n=16)$ in patients entered from 3 to $9 \mathrm{~h}$ after symptom onset if they demonstrated a PWI/DWI ratio of $>1.2$. This study was halted for safety reasons when it became apparent that both the lower and upper doses produced excessive symptomatic hemorrhage frequencies of 23.5 and $30.8 \%$, respectively. A proper dose-escalation study comparing $62.5,90$ and $125 \mu \mathrm{g} / \mathrm{kg}(\mathrm{n}=15$ each) with placebo $(\mathrm{n}=11)$ confirmed recanalization in 10 of 15 patients at the $125-\mu \mathrm{g} / \mathrm{kg}$ dose. A second phase II blinded placebo-controlled three-arm dose-finding efficacy study was then performed (DEDAS) comparing 90 $\mu \mathrm{g} / \mathrm{kg}(\mathrm{n}=14) \mathrm{rDS}-\mathrm{PA}, 125 \mu \mathrm{g} / \mathrm{kg}(\mathrm{n}=15) \mathrm{rDS}-\mathrm{PA}$, and placebo $(\mathrm{n}=8)$ under the same conditions as DIAS. In the intention-to-treat analysis, no hemorrhages were observed and 8 of 15 patients demonstrated recanalization at the $125-\mu \mathrm{g} / \mathrm{kg}$ dose, supporting the observations of the revised DIAS. The frequency of symptomatic hemorrhage was acceptable. It was claimed that in the target population significant improvement in 90-day 'good out- come' as defined by the investigators was observed at the higher dose $(p=0.022)$. Armed with these data, a phase III blinded three-arm placebo-controlled dose-finding efficacy trial (DIAS-2) was performed comparing $90 \mu \mathrm{g} /$ $\mathrm{kg}$ rDS-PA, $125 \mu \mathrm{g} / \mathrm{kg}$ rDS-PA, and placebo under the same conditions as DIAS and DEDAS. On 31 May, 2007, the sponsor reported no efficacy from this trial $[73,74]$. The program was halted.

In summary, only rt-PA (alteplase) has been associated with improvement in clinical outcome among ischemic stroke patients treated within $3 \mathrm{~h}$ of symptom onset, implying that recanalization could be translated through the microvasculature to preserve neuron function. Otherwise, with the exception of two early small studies, none have correlated documented flow or recanalization with neuron function. Studies of MCA occlusion and restitution of flow in the nonhuman primate were the first to demonstrate that perfusion is associated with decreased injury volume $[75,76]$.

Another potential clinical test of the microvessel-neuron relationship was attempted by two prospective studies of acute intra-arterial delivery of recombinant single chain u-PA (scu-PA or pro-UK) in patients with proximal MCA occlusions [71, 77]. A prospective double-blind placebo-controlled level I dose-finding study (Prourokinase in Acute Cerebral Thromboembolism, PROACT) compared recombinant scu-PA $(6 \mathrm{mg})$ with placebo in patients treated within $6 \mathrm{~h}$ of symptom onset for recanalization of M1 and M2 segment MCA occlusions and safety [71]. Both the significant increase in MCA recanalization and hemorrhage observed in the scu-PA group were heparin-dependent. A follow-on study, PROACT-2, prospectively tested the effect of intra-arterial recombinant scu-PA ( $9 \mathrm{mg}$ ) against no instrumentation for recanalization and disability outcome in an unblinded fashion [77]. Recanalization was marginally significantly increased with recombinant scu-PA (65.7\%) compared to no intervention (18.0\%), and the frequency of symptomatic intracerebral hemorrhage also increased. Disability outcome measured as $\mathrm{mRS}=0-2$ improved in the scu-PA cohort, but was not significantly different from the control group when measured as $\mathrm{mRS}=0-1$. The program was halted after regulatory review requested a third study. While two studies indicated that acute restitution of perfusion of the occluded territory was feasible using intra-arterial infusion, any benefit observed was marginal and has not been improved upon. No prospective properly controlled studies of this problem have been undertaken since. 


\section{Hemorrhagic Transformation and Acute Plasminogen Activator Use}

Focal ischemia is accompanied by hemorrhagic transformation in the areas of ischemic injury in up to $65 \%$ of patients and select focal ischemia models $[78,79]$. These hemorrhagic events can be either hemorrhagic infarction (HI, petechial to confluent petechial hemorrhages), parenchymal hemorrhage $(\mathrm{PH}$, hematomas causing mass effect and most often clinical worsening), or a combination [58].

HI appears to represent local leakage of erythrocytes from microvessels within the ischemic core regions when the basal lamina matrix is degraded. The disruption of the microvascular matrix barrier has been suggested to correspond to matrix protease generation by proximity, timing, sources, and the upregulation of specific protease activation systems (fig. 1) [24, 32]. Extravasation of blood elements leads to fibrin generation from fibrinogen within the leaked plasma. Although a large molecule (360 $\mathrm{kDa}$ ), fibrinogen appears in the extravascular space within several hours of MCA occlusion, indicating that leakage can be initiated rapidly as some microvessels are displaying evidence of occlusion (focal 'no-reflow').

$\mathrm{PH}$ has been attributed to degradation of the structure of large microvessels under arterial pressure [78]. Importantly, the risk of detectable hemorrhage appears to depend upon the presence of antithrombotics, and their dose and target. For instance, highest incidences of $\mathrm{PH}$ are associated with the use of plasminogen activators. The substrates of plasmin include fibrin(ogen), in addition to the matrix proteins laminin and collagen (as well as myelin basic protein). Hemorrhage could be accentuated when uninhibited plasmin degrades extravascular fibrin, thereby preventing the sustained formation of a fibrin network and hemostatic thrombus [58]. In this setting, clinically, $\mathrm{PH}$ frequency depends upon a number of known risk factors (table 4). Coagulation inhibitors, and to a lesser degree antiplatelet agents, accentuate hemorrhage by decreasing fibrin formation or by decreasing the activation of platelets and their participation in thrombus formation, respectively. Hence, the incidence of $\mathrm{PH}$ is dependent upon modulation of hemostasis and vascular stability.

PH impedes neuron preservation or salvage. This appears to be at least population dependent. In the NINDSsponsored study, the frequency of PH was significantly greater among those patients receiving rt-PA (6.4\%) than among those who received placebo $(0.6 \%)$ at 3 months. While mortality was unchanged, intracerebral hemor-

Neurovascular Responses to Focal Ischemia
Table 4. Factors affecting hemorrhagic transformation with plasminogen activators

\begin{tabular}{ll}
\hline Factor & Agent \\
\hline Time from symptom onset & rt-PA (d) \\
Diastolic hypertension & rt-PA \\
Low body mass & rt-PA \\
Age & rt-PA \\
Atrial fibrillation & rt-PA \\
'Early signs' of ischemia & rt-PA \\
& rscu-PA \\
\hline
\end{tabular}

rhage contributed to demise in the rt-PA group [48]. In ECASS, the frequency of $\mathrm{PH}$ associated with rt-PA exposure was higher, as was that of the placebo group [64]. Similarly, in ECASS-II PH in both treatment groups exceeded that of the NINDS study, but was intermediate with respect to ECASS [66]. A survey of the CNS hemorrhagic events in recent trials of acute thrombolysis indicates that the increased incidence of $\mathrm{PH}$ among patients treated acutely with rt-PA is directly related to the incidence of $\mathrm{PH}$ in the placebo population, and that this varies from study to study. Therefore, one might postulate that in the instance of $\mathrm{PH}$ the extent of neurovascular unit recovery depends upon attributes of individual patients or patient groups.

\section{The Neurovascular Unit - Reprise}

As a framework for understanding acute intervention responses during ischemic stroke, further basic information is required that adequately relates microvascular responses to neuron integrity in mammalian systems. The observations of matrix-matrix receptor interactions within cerebral microvessels and the rapid expression of matrix-sensitive proteases under normoxic and ischemic conditions provide starting points for dissecting the direction and consistency of microvessel-neuron communication. Those ongoing studies do not yet examine how these processes affect neuron excitability and membrane function, but they do indicate how many levels of function within the neurovascular framework are still not understood. One implication of this paucity of information and the clinical trial experience so far is that interventions that rely solely upon 'neuron protection' may be wholly inadequate to achieve clinical benefit. Strategies that extend to structural integrity and astrocyte function 
may be revealing. A more fundamental understanding of the cell-cell, and hence tissue functional, interrelationships is necessary.

\section{Conclusions}

When distanced from considerations of the intracellular processes within neurons and glia initiated by focal ischemia in the brain, the perspective that a coordinated response by neurons and their microvessels is initiated by occlusion of brain-supplying artery(ies) allows enquiry into the relevance of the intracellular and cellular responses of the entire 'unit' to tissue fate. Cell and tissue model studies indicate the importance of microvesselneuron relationships in the setting of focal ischemia. Historically, considerations of injury mechanisms have focused on the sensitivity of the neuron to ischemia; but more recent observations indicate that microvessel responses to ischemia and neuron injury occur simultaneously and in the same regions. The coordinate and potentially unitary nature of these relationships is suggested by known matrix responses to focal ischemia. These have been further supported by the integrin receptor and dystroglycan responses of microvascular endothelial cells and astrocytes to experimental ischemia (e.g. oxygen- glucose deprivation). They support the hypothesis that in the CNS events within microvessels are linked to the actions of neurons supplied by those microvessels, via a syncytium of astrocytes, and that strategies designed to protect neurons during focal ischemia should also protect function within the entire neurovascular unit.

The importance of the microvasculature to stroke outcome offers a clinical setting for this hypothesis. Among treatment approaches to ischemic stroke, the management of vascular targets has been the most successful, while other targets within the neurovascular unit have been so far uniformly unsuccessful. Both these clinical observations and the hypothesis imply the need to understand interactions within the neurovascular unit better.

\section{Acknowledgement}

We wish to acknowledge the support of the grant R37 NS 038710 and the R01s NS 053716 and NS 026945 from the National Institutes of Health.

\section{Disclosure Statement}

There is no commercial support for this work and are no commercial relationships to disclose.

\section{References}

1 Iadecola C: Neurovascular regulation in the normal brain and in Alzheimer's disease. Nat Rev Neurosci 2004;5:347-360.

$\checkmark 2$ Zonta M, Angulo M, Gobbo S, et al: Neuronto-astrocyte signaling is central to the dynamic control of brain microcirculation. Nat Neurosci 2003;6:43-50.

3 Nedergaard M, Ransom BR, Goldman SA: New roles for astrocytes: redefining the functional architecture of the brain. Trends Neurosci 2003;26:523-530.

-4 del Zoppo GJ, Mabuchi T: Cerebral microvessel responses to focal ischemia. J Cereb Blood Flow Metab 2003;23:879-894.

5 del Zoppo GJ, Milner R: Integrin-matrix interactions in the cerebral microvasculature. Arterioscler Thromb Vasc Biol 2006;26: 1966-1975.

6 Liesi P: Do neurons in the vertebrate CNS migrate on laminin? EMBO J 1985;4:11631170.

-7 Engvall E, Davis GE, Dickerson K, Ruoslahti E, Varon S, Manthorpe M: Mapping of domains in human laminin using monoclonal antibodies: localization of the neurite-promoting site. J Cell Biol 1986;103:2457-2465.
8 Herken R, Gotz W, Thies M: Appearance of laminin, heparan sulphate proteoglycan and collagen type IV during initial stages of vascularisation of the neuroepithelium of the mouse embryo. J Anat 1990;169:189-195.

-9 David S, Braun PE, Jackson DL, Kottis V, McKerracher L: Laminin overrides the inhibitory effects of peripheral nervous system and central nervous system myelin-derived inhibitors of neurite growth. J Neurosci Res 1995;42:594-602.

10 Grant DS, Kleinman HK: Regulation of capillary formation by laminin and other components of the extracellular matrix. EXS 1997;79:317-333.

11 Bernstein JJ, Getz R, Jefferson M, Kelemen M: Astrocytes secrete basal lamina after hemisection of rat spinal cord. Brain Res 1985;327:135-141.

12 Hurwitz AA, Berman JW, Rashbaum WK, Lyman WD: Human fetal astrocytes induce the expression of blood-brain barrier specific proteins by autologous endothelial cells. Brain Res 1993;625:238-243.
13 Nagano N, Aoyagi M, Hirakawa K: Extracellular matrix modulates the proliferation of rat astrocytes in serum-free culture. Glia 1993;8:71-76.

14 Furuse M, Hirase T, Itoh M, et al: Occludin: a novel integral membrane protein localizing at tight junctions. J Cell Biol 1993;123: $1777-1788$

15 Itoh M, Nagafuchi A, Yonemura S, KitaniYasuda T, Tsukita S, Tsukita S: The $220-\mathrm{kD}$ protein colocalizing with cadherins in nonepithelial cells is identical to ZO-1, a tight junction-associated protein in epithelial cells: cDNA cloning and immunoelectron microscopy. J Cell Biol 1993;121:491-502.

16 Furuse M, Itoh M, Hirase T, et al: Direct association of occludin with ZO-1 and its possible involvement in the localization of occludin at tight junctions. J Cell Biol 1994;127: 1617-1626.

17 Furuse M, Sasaki H, Tsukita S: Manner of interaction of heterogeneous claudin species within and between tight junction strands. J Cell Biol 1999;147:891-903. 
18 Hurwitz AA, Berman JW, Rashbaum WK, Lyman WD: Human fetal astrocytes induce the expression of blood-brain barrier specific proteins by autologous endothelial cells. Brain Res 1993;625:238-243.

-19 Mabuchi T, Lucero J, Feng A, Koziol JA, del Zoppo GJ: Focal cerebral ischemia preferentially affects neurons distant from their neighboring microvessels. J Cereb Blood Flow Metab 2005;25:257-266.

20 Bär T: Morphometric evaluation of capillaries in different laminae of rat cerebral cortex by automatic image analysis: changes during development and aging; in Cervos-Navarro J (ed): Advances in Neurology. New York, Raven Press, 1978, pp 1-9.

21 Bär T: The vascular system of the cerebral cortex. Adv Anat Embryol Cell Biol 1980;59: $1-62$.

22 Bär T: Patterns of vascularization in the developing cerebral cortex. Ciba Found Symp 1983;100:20-36.

-23 Milner R, Hung S, Wang X, Spatz M, del Zoppo GJ: The rapid decrease in astrocyte-associated dystroglycan expression by focal cerebral ischemia is protease-dependent. J Cereb Blood Flow Metab 2008;28:812-823.

24 Hamann GF, Okada Y, Fitridge R, del Zoppo GJ: Microvascular basal lamina antigens disappear during cerebral ischemia and reperfusion. Stroke 1995;26:2120-2126.

25 Carlson SS, Hockfield S: Central nervous system; in Comper WD (ed): Extracellular Matrix. Melbourne, Harwood Academic Publishers, 1996, vol 1, pp 1-23.

26 Webersinke G, Bauer H, Amberger A, Zach $\mathrm{O}$, Bauer HC: Comparison of gene expression of extracellular matrix molecules in brain microvascular endothelial cells and astrocytes. Biochem Biophys Res Commun 1992;189:877-884.

-27 del Zoppo GJ, Schmid-Schönbein GW, Mori E, Copeland BR, Chang CM: Polymorphonuclear leukocytes occlude capillaries following middle cerebral artery occlusion and reperfusion in baboons. Stroke 1991;22: 1276-1284.

28 Dore-Duffy P: Pericytes: pluripotent cells of the blood brain barrier. Curr Pharm Des 2008;14:1581-1593.

-29 Milner R, Hung S, Wang X, Berg GI, Spatz M, del Zoppo GJ: Responses of endothelial cell and astrocyte matrix-integrin receptors to ischemia mimic those observed in the neurovascular unit. Stroke 2008;39:191-197.

-30 Haring HP, Akamine P, Habermann R, Koziol JA, del Zoppo GJ: Distribution of integrinlike immunoreactivity on primate brain microvasculature. J Neuropathol Exp Neurol 1996;55:236-245.

- 31 Nouvel C, Caranobe C, Sie P, Capdeville J, Pris J, Boneu B: Platelet volume, density, and 5 HT organelles (mepacrine test) in acute leukemia. Scand J Haematol 1978;21:421-426.
Hamann GF, Okada Y, del Zoppo GJ: Hemorrhagic transformation and microvascular integrity during focal cerebral ischemia/reperfusion. J Cereb Blood Flow Metab 1996; 16:1373-1378.

33 Wagner S, Tagaya M, Koziol JA, Quaranta V, del Zoppo GJ: Rapid disruption of an astrocyte interaction with the extracellular matrix mediated by integrin alpha 6 beta 4 during focal cerebral ischemia/reperfusion. Stroke 1997;28:858-865.

34 Tagaya M, Liu KF, Copeland B, et al: DNA scission after focal brain ischemia. Temporal differences in two species. Stroke 1997;28: 1245-1254.

35 Tagaya M, Haring HP, Stuiver I, et al: Rapid loss of microvascular integrin expression during focal brain ischemia reflects neuron injury. J Cereb Blood Flow Metab 2001;21: 835-846.

36 Abumiya T, Lucero J, Heo JH, et al: Activated microvessels express vascular endothelial growth factor and integrin alpha(v)beta3 during focal cerebral ischemia. J Cereb Blood Flow Metab 1999;19:1038-1050.

37 Heo JH, Lucero J, Abumiya T, Koziol JA, Copeland BR, del Zoppo GJ: Matrix metalloproteinases increase very early during experimental focal cerebral ischemia. J Cereb Blood Flow Metab 1999;19:624-633.

- 38 Chang DI, Hosomi N, Lucero J, et al: Activation systems for matrix metalloproteinase-2 are upregulated immediately following experimental focal cerebral ischemia. J Cereb Blood Flow Metab 2003;23:1408-1419.

39 Fukuda S, Fini CA, Mabuchi T, Koziol JA, Eggleston LL, del Zoppo GJ: Focal cerebral ischemia induces active proteases that degrade microvascular matrix. Stroke 2004;35: 998-1004.

40 Derrick J, Shattil S, Poncz M, Gruppo R, Gartner T: Distinct domains of alphaIIbbeta3 support different aspects of outside-in signal transduction and platelet activation induced by LSARLAF, and alphaIIbbeta3 interacting peptide. Thromb Haemost 2001; 86:894-901.

41 Lees KR, Barer D, Ford GA, et al: Tolerability of NXY-059 at higher target concentrations in patients with acute stroke. Stroke 2003;34:482-487.

42 Lees KR, Zivin JA, Ashwood T, et al: NXY059 for acute ischemic stroke. N Engl J Med 2006;354:588-600.

43 AstraZeneca: AstraZeneca announces SAINT II Trial Results Showed No Efficacy in Acute Ischaemic Stroke. 2006. http:// www.astrazeneca.com/pressrelease/5279. aspx.

44 Shuaib A, Lees KR, Lyden P, et al: NXY-059 for the treatment of acute ischemic stroke. N Engl J Med 2007;357:562-571.

$\checkmark 45$ Koziol JA, Feng AC: On the analysis and interpretation of outcome measures in stroke clinical trials: lessons from the SAINT I study of NXY-059 for acute ischemic stroke. Stroke 2006;37:2644-2647.
46 Kontos CD, Wei EP, Williams JI, Kontos HA, Povlishock JT: Cytochemical detection of superoxide in cerebral inflammation and ischemia in vivo. Am J Physiol 1992;263:H1234H1242.

47 Mohr J, Thompson J, Lazar R, et al: A comparison of warfarin and aspirin for the prevention of recurrent ischemic stroke. $\mathrm{N}$ Engl J Med 2001;345:1444-1451.

48 The National Institutes of Neurological Disorders and Stroke rt-PA Stroke Study Group: Tissue plasminogen activator for acute ischemic stroke. N Engl J Med 1995;333:15811587.

49 Robbins KC: The plasminogen-plasmin system; in Comerota AJ (ed): Thrombolytic therapy for peripheral vascular disease. Philadelphia, JB Lippincott, 1995, pp 41-65.

50 Rijken DC: Structure/function relationships of t-PA; in Kluft C (ed): Tissue Type Plasminogen Activator (t-PA): Physiological and Clinical Aspects. Boca Raton, CRC Press, 1988, vol 1, pp 101-122.

51 Ranby M, Bergsdorf N, Nilsson T: Enzymatic properties of the one- and two-chain form of tissue plasminogen activator. Thromb Res 1982;27:175-183.

52 Ranby M, Bergsdorf N, Norrman B, Svenson E, Wallen P: Tissue plasminogen activator kinetics; in Davison JF, Bachmann F, Bouvier CA, Kruithof EKO (eds): Progress in Fibrinolysis. New York, Churchill-Livingstone, 1982, vol 6, p 182

53 Paoni N, Keyt B, Refino C, et al: A slow clearing, fibrin-specific, PAI-1 resistant variant of t-PA T103N, KHRR 296-299 AAAA. Thromb Haemost 1993;70:307-312.

54 Guzzetta AW, Basa LJ, Hancock WS, Keyt BA, Bennett WF: Identification of carbohydrate structures in glycoprotein peptide maps by the use of LC/MS with selected ion extraction with special reference to tissue plasminogen activator and a glycosylation variant produced by site directed mutagenesis. Anal Chem 1993;65:2953-2962.

55 Schleuning WD, Donner P: Desmodus rotundus (common vampire bat) salivary plasminogen activator; in Bachmann $\mathrm{F}$ (ed): Fibrinolytics and Antifibrinolytics. Berlin, Springer, 2001, pp 451-472.

- 56 Witt W, Baldus B, Bringmann P, Cashion L, Donner P, Schleuning WD: Thrombolytic properties of Desmodus rotundus (vampire bat) salivary plasminogen activator in experimental pulmonary embolism in rats. Blood 1992;79:1213-1217.

57 Gulba DC, Praus M, Witt W: DSPA alpha properties of the plasminogen activators of the vampire bat Desmodus rotundus. Fibrinolysis 1995;9:91-96.

58 del Zoppo GJ, Poeck K, Pessin MS, et al: Recombinant tissue plasminogen activator in acute thrombotic and embolic stroke. Ann Neurol 1992;32:78-86. 
59 Sato PH, Hall ED: Tirilazad mesylate protects vitamins $\mathrm{C}$ and $\mathrm{E}$ in brain ischemiareperfusion injury. J Neurochem 1992;58: 2263-2268.

60 Yamaguchi T: Intravenous rt-PA in acute embolic stroke; in Hacke W, del Zoppo GJ, Hirschberg M (eds): Thrombolytic Therapy in Acute Ischemic Stroke. Heidelberg, Springer, 1991, pp 168-174.

61 Mori E, Yoneda Y, Ohkawa S, Yoshida T, Ohsumi Y, Tabuchi M, Yamadori A, Kitano K, Tsutsumi A: Double-blind placebo-controlled trial of intravenous recombinant tissue plasminogen activator (rt-PA) in acute carotid stroke (abstract). Neurology 1991; 41(suppl 1):347.

62 del Zoppo GJ, Ferbert A, Otis S, et al: Local intra-arterial fibrinolytic therapy in acute carotid territory stroke: a pilot study. Stroke 1988;19:307-313.

-63 Mori E, Tabuchi M, Yoshida T, Yamadori A: Intracarotid urokinase with thromboembolic occlusion of the middle cerebral artery. Stroke 1988; 19:802-812.

64 Hacke W, Kaste M, Fieschi C, et al: Intravenous thrombolysis with recombinant tissue plasminogen activator for acute hemispheric stroke. The European Cooperative Acute Stroke Study (ECASS). JAMA 1995;274: 1017-1025.

-65 Hacke W, Bluhmki E, Steiner T, et al: Dichotomized efficacy end points and global endpoint analysis applied to the ECASS intention-to-treat data set: post hoc analysis of ECASS I. Stroke 1998;29:2073-2075.

66 Hacke W, Kaste M, Fieschi C, et al: Randomised double-blind placebo-controlled trial of thrombolytic therapy with intravenous alteplase in acute ischaemic stroke (ECASS II). Lancet 1998;352:1245-1251.

-67 Wahlgren N, Ahmed N, Davalos A, et al: Thrombolysis with alteplase for acute ischaemic stroke in the Safe Implementation of Thrombolysis in Stroke-Monitoring Study (SITS-MOST): an observational study. Lancet 2007;369:275-282.

-68 Ueda T, Hatakeyama T, Kumon Y, Sakaki S, Uraoka T: Evaluation of risk of hemorrhagic transformation in local intra-arterial thrombolysis in acute ischemic stroke by initial SPECT. Stroke 1994;25:298-303.
69 Larrue V, von Kummer R, del Zoppo GJ, Bluhmki E: Hemorrhagic transformation in acute ischemic stroke: potential contributing factors in the European Cooperative Acute Stroke Study. Stroke 1997;28:957-960.

70 Larrue V, von Kummer RR, Muller A, Bluhmki E: Risk factors for severe hemorrhagic transformation in ischemic stroke patients treated with recombinant tissue plasminogen activator: a secondary analysis of the European-Australiasian Acute Stroke Study (ECASS II). Stroke 2001;32:438-441.

71 del Zoppo GJ, Higashida RT, Furlan AJ, et al: PROACT: a phase II randomized trial of recombinant pro-urokinase by direct arterial delivery in acute middle cerebral artery stroke. PROACT Investigators. Prolyse in Acute Cerebral Thromboembolism. Stroke 1998;29:4-11.

72 Haley EC Jr, Lyden PD, Johnston KC, Hemmen TM: A pilot dose-escalation safety study of tenecteplase in acute ischemic stroke. Stroke 2005;36:607-612.

773 Hacke W, Albers G, Al-Rawi Y, et al: The Desmoteplase in Acute Ischemic Stroke Trial (DIAS): a phase II MRI-based 9-hour window acute stroke thrombolysis trial with intravenous desmoteplase. Stroke 2005;36:6673.

74 Furlan AJ, Eyding D, Albers GW, et al: Dose Escalation of Desmoteplase for Acute Ischemic Stroke (DEDAS): evidence of safety and efficacy 3 to 9 hours after stroke onset. Stroke 2006;37:1227-1231.

75 del Zoppo GJ, Copeland BR, Harker LA, et al: Experimental acute thrombotic stroke in baboons. Stroke 1986;17:1254-1265.

76 Young AR, Touzani O, Derlon JM, Sette G, MacKenzie ET, Baron JC: Early reperfusion in the anesthetized baboon reduces brain damage following middle cerebral artery occlusion: a quantitative analysis of infarction volume. Stroke 1997;28:632-637.

77 Furlan AJ, Higashida R, Wechsler L, Schulz G; PROACT II Investigators: PROACT II: Recombinant Prourokinase (r-ProUK) in Acute Cerebral Thromboembolism: initial trial results - The PROACT II Investigators (abstract). Stroke 1999;30:202.

78 Fisher CM, Adams RD: Observations on brain embolism with special reference to the mechanism of hemorrhagic infarction. J Neuropathol Exp Neurol 1951;10:92-94.

79 Fisher CM, Adams RD: Observations on brain embolism with special reference to hemorrhage infarction; in Furlan AJ (ed): The Heart and Stroke. Exploring Mutual Cerebrovascular and Cardiovascular Issues. New York, Springer, 1987, pp 17-36.
80 Abe T, Kazama M, Naito I, et al: Clinical evaluation for efficacy of tissue culture urokinase (TCUK) on cerebral thrombosis by means of multicenter double-blind study. Blood Vessel 1981;12:321-341.

81 Abe T, Kazawa M, Naito I, et al: Clinical effect of urokinase $(60,000$ units/day) on cerebral infarction - comparative study by means of multiple center double blind test. Blood Vessel 1981;12:342-358.

82 Atarashi J, Otomo E, Araki G, Itoh E, Togi H, Matsuda T: Clinical utility of urokinase in the treatment of acute stage of cerebral thrombosis: multi-center double-blind study in comparison with placebo. Clin Eval 1985; 13:659-709.

83 Otomo E, Araki G, Itoh E, Tohgi H, Matuda $\mathrm{T}$, Atarashi J: Clinical efficacy of urokinase in the treatment of cerebral thrombosis. Clin Eval 1985;13:711-751.

84 Otomo E, Tohgi H, Hirai S, et al: Clinical efficacy of AK-124 (tissue plasminogen activator) in the treatment of cerebral thrombosis: study by means of multi-center double blind comparison with urokinase. Yakuri To Chiryo 1988;16:3775-3821

85 Abe T, Terashi A, Tohgi H, Sasoh S, Naito I: Clinical efficacy of intravenous administration of SM-9527 (t-PA) in cerebral thrombosis. Clin Eval 1990;18:39-69.

86 Haley EC Jr, Brott TG, Sheppard GL, et al: Pilot randomized trial of tissue plasminogen activator in acute ischemic stroke. Stroke 1993;24:1000-1004.

-87 The Multicenter Acute Stroke Trial - Europe Study Group: Thrombolytic therapy with streptokinase in acute ischemic stroke. N Engl J Med 1996;335:145-150.

88 Donnan GA, Davis SM, Chambers BR, et al: Trials of streptokinase in severe acute ischaemic stroke. Lancet 1995;345:578-579.

89 Multicenter Acute Stroke Trial-Italy (MASTI) Group: Randomised controlled trial of streptokinase, aspirin, and combination of both in treatment of acute ischaemic stroke. Lancet 1995;346:1509-1514.

90 Hacke W, Kaste M, Bluhmki E, Brozman M, Dávalos A, Guidetti D, Larrue V, Lees KR, Medeghri Z, Machnig T, Schneider D, von Kummer R, Wahlgren N, Toni D; ECASS Investigators: Thrombolysis with alteplase 3 to 4.5 hours after acute ischemic stroke. $\mathrm{N}$ Engl J Med 2008;359:1317-1329. 